\title{
Organizational Conflict in Caring Climate
}

\author{
Shi shengpeng \\ University of Colorado Denverd \\ China \\ Mail: SHENGPENG.SHI@UCDENVER.EDU
}

\begin{abstract}
This paper explores 1) the sources of conflicts with caring climate in workplace, 2) the different figures and aspects of the conflicts occurring in the caring climates compared with the individualistic and competitive climates, 3) and the proper organizational conflict management. By a real case analysis, the paper suggests that even though the relationship of superiorsubordinate is very close, they need to use the proper ways to communicate, keeping the hierarchy system in the minds and resolve the conflicts both in content and relationship dimensions.
\end{abstract}

Keywords-Organizational communication; Face-saving; Caring climate; Conflict management

\section{INTRODUCTION}

In Chinese companies, it is very common that the leaders intend to build a brotherhood or sisterhood relationship within their departments in order to create a more caring climate. Within the brotherhood or sisterhood relationship, the organizational hierarchy system seems to be weakened that the leaders talk with their subordinates in a more caring and casual styles instead of ordering or demanding them directly. For subordinates, they might enjoy the family-like relationship and appreciate the leaders' helpfulness, kindness and respectfulness, which could contribute to the higher level of job satisfaction and organizational commitment [1-3]

Both Chinese traditional Confucian values of face-saving and the result of higher level of job satisfaction and organizational commitment contribute the companies to create the caring climate in the organizations. However, the brotherhoods or sisterhoods they build within workplace could not totally be avoided the vertical organizational conflicts between the parties to a superior-subordinate relationship. When the conflicts occur, they might be more complicated compared with the individualistic or competitive climates. There are three major problems in this situation. Firstly, as the leaders how to excise their power of being the bosses in hierarchy system and to let the subordinates follow their orders properly. Secondly, for they have already built the brotherhoods or sisterhoods relationship, the conflicts might be more complex [5-6]. They are not only about the content of the conflict but also about their friendly relationship. Thus, the goals of conflicts might be changed easily during the conflicts, which promote the complexity of the conflict [7-8]. Thirdly, how to deal with the conflicts and to find the resolutions are significant. They are about how to save the faces for "brothers" and "sisters" and continue to work together like before. Otherwise, the outcomes of the conflicts could become destructive that the face-losing issue would become the tension and blocks in the future.

\section{Objectives of the paper}

To find out some possible reasons the conflicts occur in the organizations with a caring climate.

To find out the different figures and aspects of the conflicts occurring in the caring climates compared with the individualistic and competitive climates.

To find out the proper tactics and managements for these conflicts, which both deal with the content of the conflicts and fix the brotherhood and sisterhood relationship in order to get the positive outcomes of the conflicts.

\section{Research Methods}

\section{A. Literature Review}

Collecting the current researches of the caring climates, Chinese face-saving values, hierarchical system, vertical and horizontal organizational conflicts to find the sources of the conflicts within the brotherhood or sisterhood relationship theoretically.

\section{B. Case Study}

Finding a real case of the conflicts and interview the two parties to analyze the how and why the conflict occurs. From the analysis, I could summarize and diagnose the sources of the conflicts and find out the possible resolutions for the conflicts.

\section{Significance of the paper}

The brotherhood or sisterhood relationship is very common in Chinese companies. It is based on the Chinese traditional values. The results of the paper could be useful to deal with the conflicts in these companies.

For subordinates, they would get better understandings the organizational relationships, especially for the graduates. They might only enjoy the friendly relationships and ignore the superiority of their bosses, which could be the potential of the conflicts.

For leaders, the result of the paper could be useful to find out the proper communication tactics, the effective conflicts management and how to prevent the conflicts in the future. 


\section{LITERATURE REVIEW}

When it comes to the organizational climate, the caring climate could be one of the ideal types that the companies intend to create. According to the scholar Fu, caring climate means the same values and beliefs known and perceived by workgroups and organization members. (Fu, 2004) Especially, in Chinese firms' settings, people think highly of organization commitments, face maintains and interpersonal relationship within the organization. In other words, plenty of Chinese firms consider the caring climate as the ideal type due to the Confucian cultural values. To build a caring climate, the leaders in the organization play important roles. It is very common in Chinese firms that the leaders of department build a family-like environment by protecting their subordinates, helping them and cooperating with them. In this way, the leaders build the brotherhoods or sisterhoods in their departments. The research also shows that the result of the caring climates is the higher level of job satisfaction and organizational commitment among the subordinates. (Fu, 2004)

Especially, in Chinese firms' settings, people think highly of organizational commitments, face maintains and harmonious interpersonal relationship within the organization. (Cheng, 1994) The Chinese traditional values of facing-saving, strong commitments and harmonious environment contribute to the brotherhood or sisterhood relationship in workplace. In other words, higher managers might not intend to demand or order frontline workers directly even though they are in different positions. These findings from scholar $\mathrm{Fu}$ could explain the motivations that the leaders intend to build the caring, family-like and friendly climate within the workplace.

However, within the organization, the hierarchy systems still exist. The directors, middle manages and frontline workers have different powers, responsibilities and tasks. These differences could not be faded out due to the caring climate. According to Scholar Thompson, the leaders have the certain rights to monopolize communication within the organization, expect obedience and loyalty from his subordinates, assign the tasks for them and to make the final decisions. (Thompson, 1967) Thus, fundamentally, the hierarchy system still exists. The people in lower positions have to follow the leaders in certain conditions. And the brotherhood or sisterhood relationship and the hierarchy system might be contradicted. The hierarchy system is not family-like. And the leaders' assignments fundamentally are the orders and demands, which could not be negotiated like the family issues.

Based upon the research, the bureaucratic model of organizational conflicts, which deal with authority relations and the need to control are the most frequent types occur in workplace even if the climate is very caring and cooperative among them. (Pondy, 1967) In other words, the result of the research shows that whether the climate is caring or not, the conflicts are like natural actions that they could not be avoided. The particular sources of conflict in the organization with the caring climate could be the leaders' communication styles and the frontline workers' misunderstanding of the vertical relationship.
Within the brotherhood or sisterhood relationship, the leaders, in order to be friendly and caring, they might use the horizontal way to communicate with the subordinates. For subordinates, they might realize the friendly and caring climate but not the hierarchical vertical relationship. However, the hierarchy system still exists in workplace fundamentally. The communication tactics from the leaders and the ignorance of hierarchical relationship from the subordinates are the major sources of the conflicts. Compared with the other types of the climates in workplace, once the conflict occurs, people need to both solve the content and relationship of the conflicts. To prevent these conflicts, the leaders should properly communicate and express the demand in a more professional way. Meanwhile, the subordinates should always keep the hierarchy systems in their minds even though they have a very friendly and family-like relationship with their bosses.

\section{CASE STUDY}

HRIE International Education Group is an education company, which aims to promote and deepen the exchange and cooperation of international education, to integrate education resources and to establish friendly cooperation with the universities and educational institutes internationally.

Mr. Hou is the director in the business development department in HRIE International Education Group. The department is mainly to develop the resources in Colleges and Universities both in China and overseas. And the company helps Chinese universities and foreign colleges to establish the Sino-foreign educational cooperation programs. Within his department $\mathrm{He}$ has already created the caring climate. His subordinates call him as "the third Brother", for he is always protecting his subordinates, helping them and cooperating with them to finish the tasks.

$\mathrm{Mr} . \mathrm{Li}$ is one of the subordinate in the department and he has a very friendly relationship with $\mathrm{Mr}$. Hou. He truly considers him as his brother who has provided plenty of professional and useful suggestion of being a BD. After the work, they often have dinner and talk about the job issues together. In other words, the relationship between Director Hou and Mr.Li has already been beyond the superior-subordinate relationship and they are more like brothers, friends and partners.

On November 12th, 2017, an office-holder of Linyi University, who is one of the major clients of HRIE, informed Director Hou that they intended to postpone the signing ceremony with a British college for all of the major leaders will be supposed to participate in the conference of learning the spirits of the 19th CPC National Congress. It could be an emergency because $\mathrm{Mr}$. Li had already made an appointment with the British College and invited the Dean to come to Shandong Province to take part in the signing ceremony.

So, Director Hou made a phone-call to Mr. Li and told him the emergency. However, this phone-call was very informative that it was not only about the changing time of the signing ceremony but also something about the other things. Mr. Li had not realized the seriousness of the emergency for the tone of Mr. Hou was very casual as usual. In this way, he did not inform the college at that day. 
Next day, when Director Hou asked Mr. Li what British college's reply of the changing time of the signing ceremony. Mr. Li said that he had not contacted them yet. His response caused Director Hou to become mad directly that he thought $\mathrm{Li}$ was unprofessional and irresponsible for his job. Meanwhile, $\mathrm{Mr}$. Li did not how to response the director's madness and become incapacitated or confused for he felt embarrassed in front of other colleagues. After that, they have experience a long-term freezing period.

\section{The Director's Perspective}

When the author interview Director Hou, why he becomes so angry about this incident, he replies that

"When I notice that little Li did not inform the British college, I suddenly lost my temper. I had already made a phone-call on my own and I thought, as a professional $\mathrm{BD}$, he should have the ability to judge the importance and the seriousness of this incident though I also told him to do something else in the phone-call."

From his response, he emphasizes that the reason why he lost the temper was to question the Mr. Li's ability to judge the seriousness of the things he was supposed to do. It is the content of the conflict. It is very common that the clients would change the date of appointment for some reasons. However, this case could be considered as a serious and important change, because it is the signing ceremony. And the whole company has already made many efforts and contributions to make the agreements between Liyi University and the British college as the third agent. Director Hou thinks that Mr. Li does not take his demands seriously and he does not inform the British college that the time of the signing ceremony would be changed. And Mr. Li truly does not inform them as soon as possible, which is his fault in this case.

However, the communication tactics of the leader also have some problems. When the emergency occurs, Director. Hou makes a phone-call as the channel to send his demands, which is unprofessional. Such an important change, he is supposed to send the e-mail to $\mathrm{Mr}$. $\mathrm{Li}$ as an official request or demands. If he sends the e-mail, the conflict might be avoided. For one thing, Mr. Li would receive a more clear and informative order that he would realize the importance of the issue and notice when he should contact the British College clearly. For another, the e-mail could become the evidence for Director Hou if $\mathrm{Li}$ does not inform the clients. Then his anger and madness could be more reasonable and he would be free from the problems.

Author: "As the director of the department, you have a good relationship with all of us. And we always consider you as our brother. So, Mr. Li does. Do you think this accident affects the relationship between you and Mr. Li? "

“As you said, I am not a very strict boss. And I always want to be friendly and helpful because I intend to provide a friendly and harmonious working environment for you. I believe that if I treat you well, you would have a stronger working ethic. However, the very important condition is that you should finish the job precisely. In workplace, it might be different from the schools that some mistakes must be avoided, because it is not only individual task but also the entire team's effort. As the leader, my job is to take charge that the whole process of the project and make sure that everyone will finish their individual tasks correctly. In this way, both you and little Li must take the tasks seriously and finish them. As for the relationship, I concern oneself with facts and not with individuals. I am angry about the facts but not him. And after the things resolved, we are still brothers."

For one thing, the director thinks highly of the caring climate in his department. He believes that a friendly and caring climate could contribute to a stronger work ethic and the subordinates could enjoy the working environment. This could explain why he intends not to be very strict and straightforward. However, in his mind, he still has the hierarchical system. As he said, the leaders are supposed to take charge the whole process of the process and to make sure the subordinates finish the tasks precisely. It is the vertical relationship in workplace. Although the brotherhood or sisterhood relationship looks like more horizontal, for the subordinates, the most important thing is still the compliance of the tasks with quality and time standards. And he provides the reasons that, in workplace, each individual task is the important part of the whole project. If some of the individual tasks fail, it could affect other efforts and contributions, which are the things we must avoid. And the way to avoid the serious mistakes is to follow the vertical demands and finish them carefully.

\section{The Subordinate's Perspective}

When the author interview Mr. Li, how he think about the this incident, he replies that "I admit that it is my fault that I did not inform the British college the changing of the signing ceremony as soon as possible. And I feel apologized about this. However, when he became mad at me, I felt very embarrassed and did not know how to deal with his anger. Also, I am more concerned about the relationship with my director. In my mind, I truly appreciate and admire him even though we had some conflicts. After this incident, it is a long time that I did not know how to face him and deal with the relationship."

From his response, what he mainly concerned about this conflict are face losing and the relationship. His embarrassment is due to the face-losing. In front of others, the madness of his director affected Li's self-esteem especially they used to be very friendly. It becomes more hurtful for Mr.Li. Even though Li still admire his brother Hou very much, he needs to be given his face back.

The reason why they have experienced the long-term freezing period is that, for $\mathrm{Mr}$. Li, the goals of the conflict has already changed to his face and their relationship. He is waiting for his direct Hou to give his face back. And both of them need to deal with their relationship like before, otherwise it could be a destructive outcome of the conflict.

It was the part that Director Hou skipped and caused the long-term freezing period between them. The leader's explanation of this is that "I am angry about the facts but not him. And after the things resolved, we are still brothers." There is no doubt that, in workplace, people should focus on the facts and the content of the content rather than the faces and relationship. However, within the caring climate and brotherhood relationship, the face and relationship become 
more important compared with the simple superior-subordinate relationship and other types of the climates.

In fact, the director has already treated Mr.Li as friendly as before. As he said, they are still brothers. However, Mr. Li might need to clarify this issue. He is concerned about their relationship for the director used to protect him helping him as the brother. If the director does not speak up clearly, $\mathrm{Mr}$. Li still have the questions that whether my leader has already forgiven me or not, which could be the tension and misunderstanding between them. Thus, for both of them, they might need to sit down and talk about this. It is the proper way to fix their brotherhood relationship.

\section{Vertical Relationship}
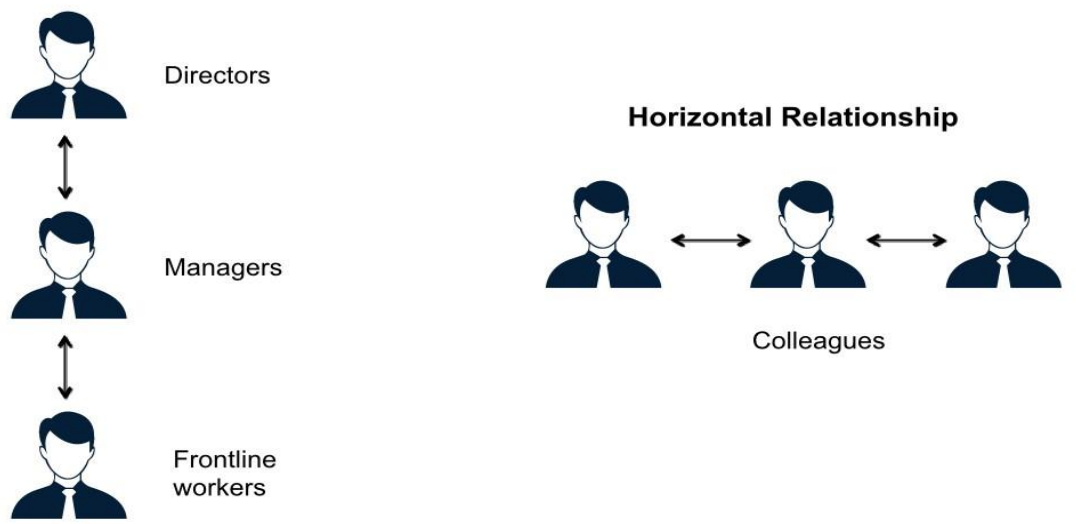

Fig. 1. Vertical Relationship and Horizontal Relationship Model, Author

\section{Diagnosis of The Conflict In CARING Climate}

From the case, there are some illuminations how to understand the brotherhood or sisterhood relationship in workplace. The brotherhood or sisterhood relationship contains both the figures of pure vertical and horizontal relationship. On the surface, the communication styles are more horizontal. Within the relationship, the leaders might use a more causal way to express their demands or needs instead of ordering them in a straightforward way. The frontline workers also use the casual way to communicate with their leader such as the "third brother" in the case. The horizontal communication tactics weaken the power and position differences. And the reasons for these horizontal communications tactics are to form a friendly and caring climate. It could contribute to a stronger work ethic, higher level of department commitment and job satisfaction.

And the vertical relationship exists in an invisible way. Fundamentally, the subordinates should follow the orders and demands from the leaders. It is the basic and fundamental element in the organizations no matter what types of the climates. Especially for leaders, the hierarchy system is very clear in their minds. They believe that it guarantees the outcome of the project. It could contribute to a higher level of efficiency of the whole project. In this way, no matter what types of the communication tactics, they require that the subordinates should take the requests from the leaders seriously and keep the hierarchy relationship in their minds.

\section{Brotherhood or Sisterhood Relationship}

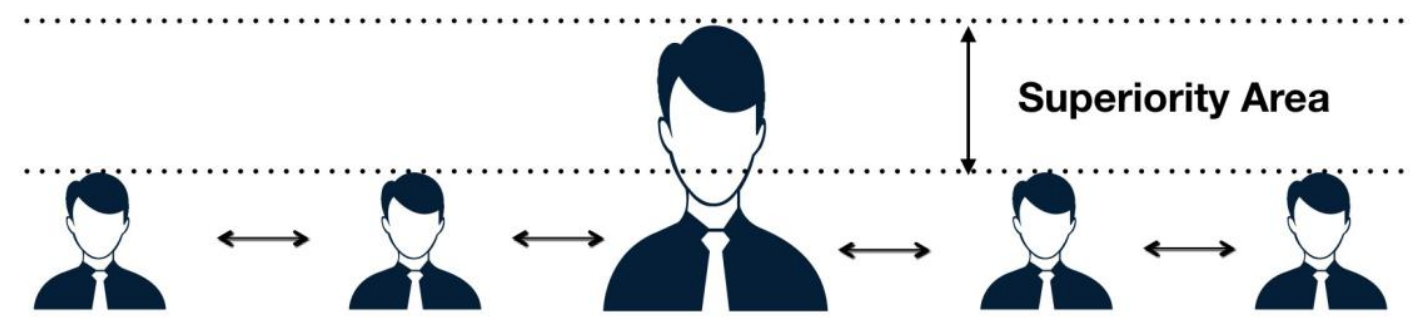

Fig. 2. Brotherhood or Siterhood Relationship, Author

And this figure visualizes the brotherhood and sisterhood more clearly. Although the communication styles are more horizontal, there are the power differences between brothers or sisters. The leaders are the older and big brothers or sisters in this relationship that they have more powers and the rights to make requests for the little brothers. And the subordinates are relatively powerless and supposed to follow their big brothers or sisters. And the superiority area is the invisible place that the leaders could excise their power. When the leaders communicate to the little brothers or sisters, the horizontal way 
could cause the subordinates forget the power differences. And the ignorance of the superiority area for the subordinates could be the major source of the conflicts among them. They might be confused about the contradiction of the caring climates and the hierarchy system. It seems that the brotherhood or sisterhood relationships are more horizontal and they might forget that the hierarchy systems are still there. Therefore, even though they are more like brothers and sisters, the bosses are the elder brothers or sisters who are more powerful that normal workers still need to obey and follow their elder brothers or sisters. These are the visual figure of the brotherhood or sisterhood relationship within the hierarchical organizations.

\section{Comparative Analysis}

Once the conflicts occur between brothers or sisters in workplace, the outcomes might become more destructive compared with the individualistic or competitive climates. For the individualistic climates, the level of trust and supportiveness is relatively lower. They follow the pure vertical and horizontal relationship clearly to finish their own individual tasks. Within the individualistic climate, the hierarchy system and the power differences are clear. "Power is likely to be used. Higher-power parties will attempt to force or pressure lower-power parties to accept their preferences." (Folger, 2013) In other words, when conflicts occur within the individualistic climate, the power differences could be the major source to deal with the content of the conflicts. They have a normal relationship in the workplace and the conflict might not affect the relationship very much. It is more about the content of the conflicts.

Within the competitive climates, the relationship of superior-subordinate is relatively hostile that they are the competitor who intend compete even defeat others. "It may not be safe to open up or express feelings openly because they may be used against us." (Folger, 2013) In other words, for the leaders, they are often defensive that they intend to protect the higher position and control the subordinates. And, for the subordinates, they might have the strongest work ethics, however, they are more competitive for their own benefits. They might attempt to take place the leaders' position and get the promotions for themselves. Thus, the indirect conflicts have already existed. When others conflicts occur, it might not be as destructive and influential compared with the caring climates. And they might not need to make as many efforts as the caring climate to fix the relational problems.

Compared with the other two major types of climates, the conflicts might be more complex in the caring climates. They are not only about the content of the conflict but also about their brotherhood or sisterhood relationships. They used to have a more cooperative relationship. When the conflicts occur, they might be more hurtful, especially for the subordinates. As the case shows, Mr. Li has already lost the face from the conflicts and he is waiting for his brothers to give his face back. If the leaders do not deal with the relational problem, the explosive conflicts would become the indirect conflicts and cause the long-term freezing period between them. In this way, the conflicts are relate to contents, the face issues and relational problems, which are more complicated in the caring climate with the brotherhood or sisterhood relationship.

\section{Conflict Management}

To find the resolutions of the conflicts, there are two major aspects to deal with. Firstly, it is the content of the conflicts. It is relatively easier to find out the proper treatments. As the other types of the organizational conflicts, the content parts could be modified or replaced as a result of the conflict. And each party could develop increased understanding of his own position because conflict forces people to articulate their views and to bring forth all supporting arguments. (Henkin, 1984) As the case shows, after the director express the reasons why he becomes mad and angry, the subordinates could easily notice and admit his faults. In this way, the content of the conflicts could be easily resolved if each party express their reasons properly.

What's more important, it is to deal with the relational problems. The former friendly and close relationship between brothers and sisters could become the pressures for the subordinates to face their older brother or sister if the relational issues have not been resolved. (Shafer, 2002) In this way, for the leaders, they might be the active parties to fix the relationship. Once the content problems have been done, the leaders should also openly speak up that the relationship would not be affected by the conflicts and what they angry or mad are only about the content but not the individual person. This could be the way to give faces back and fix the relationship between them. In a word, the process of the conflict managements should contain two parts. They should figure out the contents issues and then to deal with the relationship by giving faces back to each other. These might be the effective managements of the conflict and contribute to the more positive and productive outcomes of the conflicts.

\section{CONCLUSION}

To draw a conclusion, within the brotherhood or sisterhood relationship, the sources of the conflicts are the causal and improper ways to send the demands from the leaders and the ignorance of the superiority area from the subordinates' perspective. Compared with the other two major types of climates, the conflicts might be more complex in the caring climates. They are not only about the content of the conflict but also about their brotherhood or sisterhood relationships. To achieve the more positive outcomes of the conflicts, each party should deal with both the content and the relationship properly to manage the conflicts.

Finally, from the analysis captured in this article, it is therefore crucial that;

For the leaders, they need to use more professional ways to send their requests such as sending the e-mails instead of the phone-calls or We-chat for avoiding the misunderstandings.

For the subordinates, no matter how close and friendly the relationships with their leaders are, they should always keep the hierarchy systems and the power differences in their mind to be more professional in workplace.

When the conflicts occur within the brotherhood or sisterhood relationship, the process of the managements should contain two parts. Each party should figure out the contents 
issues and then to deal with the relationship by giving faces back to each other.

\section{REFERENCES}

[1] Folger, J. P., Poole, M. S., \& Stutman, R. K. (2013). Working through conflict:Strategies for relationships, groups, and organizations (7th edition). Boston: Pearson Education, Inc.

[2] Thompson, V. (1961). Hierarchy, Specialization, and Organizational Conflict. Administrative Science Quarterly, 5(4), 485-521.

[3] Chen, G. M., Chung, J. (1994). The impact of Confucianism onorganizational communication. Communication Quarterly, 42, 93-105.

[4] Pondy, L. (1967). Organizational Conflict: Concepts and Models. Administrative Science Quarterly, 12(2), 296-320. doi:10.2307/2391553.

[5] Henkin, A., \& Singleton, C. (1984). CONFLICT AS AN ASSET: AN

[6] ORGANIZATIONAL PERSPECTIVE. International Review of Modern Sociology, 14(2), 207-220.

[7] Fu, W., \& Deshpande, S. P. (2014). The impact of caring climate, job satisfaction, and organizational commitment on job performance of employees in a China's insurance company. Journal of Business Ethics, 124(2), 339-349.

[8] Shafer, W. (2002). Ethical Pressure, Organizational-Professional Conflict, and Related Work Outcomes among Management Accountants. Journal of Business Ethics, 38(3), 263-275. 